\title{
Reforms in the western residency training programs over the last 15 years: Considerations to note when setting our domestic program
}

\author{
Hisham El-Akkad, MD FRCS(I) \\ Department of General Surgery, Ain-Shams University, Cairo, Egypt.
}

Nowadays, there is an increasing consensus in the Egyptian community about the need for educational reforms in all fields and at all levels. Among the surgical community, there is a generalized conception that the postgraduate training at the present time is not effective in producing young surgeons capable of meeting the desired level of competence and of providing a satisfactory degree of health care service in their field of specialty. Unfortunately, we do not have a defined and audited training residency program in surgery yet. In the western community, such training programs date many years ago. Still over the last 15 years a lot of reforms were made to those programs with added advantages but also with some drawbacks. If we decide to establish a training program for our surgery residents, as we should, then a review of the recent developments in these programs in the western countries might help draw our attention to certain considerations. Probably we will start our domestic program in our university hospitals but definitely this will need to extend to all teaching hospitals nation wide. The reason to start with university hospitals is that working in a medical school has been proved to represent a well-balanced model of time allocation between patient care, research and education compared to other models. ${ }^{1}$

Unlike huge western publications, I found no reference studies assessing the training of surgery residents in Egypt. I will have to rely on personal knowledge when referring to the situation in our university hospitals in Egypt assuming that there are no big differences between the ways surgery residents are trained in my university of Ain-Shams and other university hospitals in Egypt.

In 1992 Kenneth Calman, then chief medical officer, set up a working group to bring the British system of specialist training into line with the requirements of the "European Medical Directives". The resulting report recommended combining the registrar and senior registrar grades into a unified specialist registrar grade and defining the curriculum and minimum training period for each specialty, the successful completion of which would lead to admission to the specialist register. Features of the new system were set out in A Guide to Specialist Registrar Training and included educational objective setting, training agreements, and induction at the start of each placement; rotational placements designed to offer specified experience; and regular feedback on progress from the supervising consultant. The reforms were to be cost neutral, and no additional resources were made available to the National Health System (NHS) trusts for their implementation. Transition to the new system began in December 1995 and was completed in April 1997. The new arrangements placed more emphasis on structured teaching and supervised learning.

Although the reforms received a cautious welcome, there were anxieties about the impact of shortening the training time on trainees' experience especially since junior doctors' hours were being reduced. It was expected that the reforms would lead to fewer trainees and more consultants. The implementation of the reforms seemed likely to create a major new training workload for consultants. ${ }^{2}$

Initial assessment, just after the implementation of the new system was conducted in the UK in 1997. The reductions in doctors' hours and the introduction of specialist training have reduced general surgical training by $60 \%$. The total number of operations required for training was compared against the total actually performed across the health board. Operating times for five representative operations were audited prospectively. The total number of operations available for training (4913) was $38 \%$ less than the number recommended (7946). Trainees required 50$75 \%$ more operating time than consultants. To increase the proportion of operations undertaken by trainees from $30 \%$ at that time 
to $70 \%$ would require an extra 270 theatre days (or $£ 1.3 \mathrm{~m}$ ) yearly. The study recommended that the minimum number of operations required for training must be defined and the proportion of supervised operations undertaken by trainees substantially increased. The study proposed specified solutions to consider:

- Purchasers, providers, and educational authorities must agree that teaching and training are in every way of equivalent value to clinical work.

- This means that the number and proportion of both supervised and unsupervised operations undertaken by trainees will have to be substantially increased.

- To accept that trainees will not receive enough training before becoming consultants and will complete their training after taking up their consultant appointment. In the early years a junior consultant may frequently require assistance from senior colleagues.

- A natural extension of this concept would be to plan the introduction of a subconsultant grade.

- To accept that the $60 \%$ reduction in trainees' overall training is excessive. Two options would be to increase the basic surgical training period by an additional year of general surgery and to permit a limited increase in the number of hours on call. ${ }^{3}$ However, two years after the implementation of the reforms trainee ratings of the educational elements of their current posts had improved; educational objective setting, induction to the post, consultant feedback, and clinical supervision were all more likely to have occurred and been satisfactory. The changes could not have occurred without considerable extra effort from consultant trainers and may not be sustainable without the consultant expansion on which the reforms were predicated. ${ }^{2}$

The changes initially made in some European countries were imposed on most other members of the European Union (EU). In Switzerland, there have been similar changes in the residency training program aiming at earlier specialization within the field of general surgery. ${ }^{4}$ In Italy, until 1992, the national health system (NHS) had a secondary role in medical education, as the 33 medical schools for postgraduate training were under the control of the Ministry of University. The European Community legislation allowing free movement of residents and specialists between member countries has resulted in standardization of teaching programs and formative curricula in the European Community. Until that time surgical training in Italy was mainly theoretic, as no legislation guaranteed that physicians in training would perform surgery. New legislation was intended to increase exchanges with European hospitals, and improve cooperation between universities. ${ }^{5}$

Traditional work schedules of surgical residents have been cited as a factor that negatively influences education and the quality of patient care. In the USA, demands by federal and state legislators as well as the general public have forced a re-evaluation of the issue. Long working hours and resulting sleep deprivation affect the lives of residents profoundly, but the question remains does it lower the quality of medical care? The justification for the long hours is that they are vital to medical education, but residents are so drained by their schedules that they are rarely in the best state of mind to learn from their experiences. To compensate for the reduced training hours, an extension of residency years will be needed. However, residents did not want to lengthen residency training beyond the 5 years. ${ }^{6}$ In Hong Kong, opinion survey was made addressing this issue. Most respondents agreed that residents' work hours should be limited. Seventy-two percent thought that the addition of physician assistants, nurse practitioners and ancillary staff could help decrease the workload of residents. More than $60 \%$ thought that residents should have postcall afternoon off. Seventy-two percent worried that the number of operations residents performed would decrease. Only half agreed that long working hours was part of resident training and $56.3 \%$ agreed that the training period should be lengthened because of limiting work hours. Ninety-four percent agreed that sleep-deprived residents would create more medical errors; $72 \%$ thought that long work hours would impair quality of care. Surprisingly, only $28 \%$ thought that limiting work hours would compromise continued patient care. $^{7}$ 
Major changes in the residency-training systems are currently under way worldwide. New laws regulating the maximum number of work-hours per week are already enforced in the USA and in the European Union (EU). The implications of the new regulations in the USA are likely to be magnified by the number of young people willing to take up Medicine as a career and even more so by the gradual decrease in the number of medical graduates who choose to take up Surgery as their specialty. An important reason is the existence of other professions allowing a more comfortable life, without the need for a lengthy and stressful education and without the engagements, the stress, and the responsibilities associated with the practice of medicine (particularly surgery). It should, however, be conceded that in a study carried out in Pakistan stress was not perceived to be an important influencing factor for those who decided to select surgical specialties. Difficulty in and uncertainty about finding a senior position for working in a reputed hospital after acquiring the necessary title or degree is another important reason for individuals to shun from becoming doctors and surgeons. The increase of the percentage of women is also observed among surgeons; in England the percentage of women surgeons has increased by around $47 \%$ between years 2000 and 2004. The percentage of women residents in surgery corresponds to about 16 $\%$, while in the rank of chief resident doctors the corresponding figure is approximately $23 \%$. In most cultures, women have considerable responsibilities on the home-front and women accord a much higher priority to familial matters than do men. It is possible that new guidelines, which have shortened the working hours for doctors and surgeons, may have resulted in attracting more women to the field of surgery. In America, till recently, residents worked about 95 hours per week on an average. Nowadays, in the USA and according to the ACGME (Accreditation Council on Graduate Medical Education) the restriction of 80 workhours per week for residents is in effect since July 1, 2003. There are also in effect some concrete regulations regarding the duration of each shift as well as the duration of obligatory resting periods for the residents. Similar regulations regarding the work-hours per week are also in effect in Australia; for the residents in Australia, a maximum of 13-14 work-hours per day is permitted. In 1993 the European Union published a directive (93/104/EC / 23 11-1993) that regulated the work-time in the EU counties. Ensuring safety and safeguarding health of resident doctors and improving their quality of life and conditions at workplace were the main motives behind promulgating the directive. In 2000 the European Parliament published a new directive (Directive 2000/34/EC) that included the residents. The principal points of this directive are:

1- By 1st August 2004, the total weekly time of work decreased to 58 hours. This regulation will be in effect up to August 2007.

2- From August 2007, this time will be progressively decreased to 56 hours.

3- From August 2009, the medium weekly time of work (including the on-call service) for the residents will be decreased to 48 hours. This planning will allow the necessary adaptations of the European countries; the period of adaptation can be extended up to 2012.

4- The minimal duration of continuous rest per 24 hours should be 11 hours (effective, August 1, 2004)

5- Break at least 20 min when the duration of work exceeds 6 hours (effective, August 1, 2004)

6- The minimal period out of work per week should be 24 hours (or at least 48 hours per 14 days) (effective, August 1, 2004)

7- The maximum duration of night work should be 8 hours (effective, August 1, 2004) 8- Annual leave should be at least 4 weeks per year (effective, August 1, 2004) Nevertheless, the restriction of work-hours per week is likely to create some problems in medical education. The obligatory absence of the residents following an on-call service will result in the loss of continuity in the care of patients. The residents stand to lose opportunities of learning that educational activities like case presentation sessions and in-service discussions provide. These changes can create a lack of responsibility in the resident doctors involved in the care of the patient and may result in the phenomena of transfer or denial of responsibility in the case of 
complication or poor outcome. In Germany, two models of on-call service have been tested (alternating in two shifts of 12 hours or alternating in three shifts of 8 hours each). The model of 12 hours is the preferred one by the majority of residents. However, in Sweden the 40 work-hours week has been in effect for a long time. The results of surgery in Sweden have consistently improved during the last 30 years and they are among the best worldwide. Nevertheless, the limited weekly work-hours has its impact on the education of residents in Sweden, where the number of cases that the residents treat is relatively small. This has been compensated for by the fact that after the acquisition of the title of specialty, an additional period of 6 to 8 years as junior specialists is required, during which the new surgeons will acquire the experience necessary to become autonomous as professionals. Therefore, the extension of duration of the postgraduate course may be another possible solution. In the Scandinavian countries, where the limited weekly work-time is in effect for more than two decades, an extended period of time (up to $10-12$ years) is required for a resident to complete the program of residency in general surgery and to acquire the title of a surgeon. ${ }^{8}$

However, in the Flemish- and Frenchspeaking parts there were general agreement that: The training of a general surgeon should not take longer than six years. The first four years should consist in a general training in surgery, the last two years being used for the sub-specialization. At the beginning of each year, the trainees should be provided with a list of the operations to be performed by the training surgeon. Lectures during working hours are preferable to those given in the evenings. The residents should be allowed to go off duty after a night on duty. An independent visitation committee, evaluating the departments, their heads and the resident trainees is needed. ${ }^{9}$

The problem is more amplified considering sub-specialties. In $87.5 \%$ of the countries paediatric surgery is recognised as a subspeciality. The mean duration of training is about 6 years and 3 months, excluding the countries where it is necessary to become a fully accredited general surgeon before doing paediatric surgery. The mean duration of stay in general surgery is 2 years and 10 months. In one third of the western countries it is obligatory to spend some time (3 to 12 months) in paediatrics. An elective or a compulsory period of time ( $1-6$ months) in other specialities such as orthopaedic surgery, plastic and reconstructive surgery, thoracic surgery and urology exists in $41.7 \%$ of the nations.

The most common subspecialties within paediatric surgery practised during the training by the resident are abdominal surgery, thoracic surgery, oncological surgery, head and neck surgery and urology. Possible means of control to guarantee a high quality of training include a defined time of stay in each subspecialty, the number of operations done by the trainee or the number of cases treated by the resident in the respective subspecialty and the distinction of different levels of surgery done by the trainee during his residence. In many cases the type of control is not specified. ${ }^{10}$

Although several reports have; at times sorely, compared old with new times, there have been a general consensus that complying with demands of time change and adapting to the new situation is inevitable. A report from St Mary's hospital - UK considered the success of old times in creating competent surgeons to be due to the considerable clinical workload and a school of surgeons that were well trained and skilled in the full breadth of general surgery. The report however recognized that the more recent surgical training standards have unavoidably adapted to both market forces and European directives on doctors' hours. The prospect of a more focused and organized training that could produce consultants by the age of 32-33 was welcomed by most. Submitting to these objectives, a tightly focused training program was recommended. ${ }^{11}$

For us as well, it is hard for the surgeons of previous generation to understand these restrictions on time for practicing their craft. Extended periods of hard work have not deprived the joy that surgeons feel on a job done well by the practice of surgery. This attitude is based on the acceptance of the fact that doctors are in a continuous war with the enemy i.e. disease, a war that lasts 24 hours of a day, 7 days of a week, 365 days a year. My and previous generations, based on our memories as residents, strongly believe, almost 
to the point of conviction, that hard work done during residency alone would guarantee the acquisition of knowledge and skills required for autonomous career as a surgeon. We believe that long unrestricted hours of work allowed us to participate in and learn about various phases of care of surgical patients and this was a small price to pay for acquiring the requisite knowledge, experience and skills for becoming a successful surgeon. We will definitely face difficulty with ourselves to develop a program that allows "un-understandable privileges" for new residents that we, ourselves, were either willingly, or compulsory deprived of. However, we have to face the challenge of overcoming our emotions and accept new standards that meet the change of time.

At the University of Washington - USA, a new rotation has been developed to provide last minute coverage for unplanned leaves of resident colleagues who are now expected to fulfill certain training tasks. This has been called EVATS rotation because residents in this rotation will fill gaps in Emergency coverage, Vacation coverage, coverage for Academic project leaves (as each resident is expected to complete one project), and coverage for Technical Skills training (including simulator courses, etc.). An EVATS rotation lasts from 4 to 8 weeks depending on Residency-level. 12

In our units we are usually faced with shortage of residents during their exam vacations. This is practically the only vacation allowed for most surgery residents. If certain training skills, including courses, will become mandatory when planning our domestic program, we have to expect increasing periods of shortage of residents. This will further be aggravated if the training years will be doubled to meet the international standards. In this situation it would be impossible to deny residents, over their 6 years of training, the right for other vacations for recreation or family activities. A means to fill in gaps will then be required.

New accreditation requirements for residency training programs require residents to have educational experiences that allow them to demonstrate competency in the following areas: (1) patient care, (2) medical knowledge, (3) practice-based learning and improvement, (4) interpersonal and communication skills, (5) professionalism, and (6) systems-based practice. ${ }^{13}$ To improve communication skills pilot programs were introduced at first year residency to create opportunities for (1) teaching essential interviewing and communication skills to trainees at the beginning of residency, (2) assessing resident skills and confidence with specific types of interview situations, (3) developing faculty teaching and assessment skills, (4) encouraging collegial interaction between faculty and new trainees, and (5) guiding residency curricular development. ${ }^{14}$

Cheap tools to keep knowledge updated and to train residents to acquire analysis and interactive skills are ideal for developing countries because of limited resources. One method is the journal club. A journal club can be defined as a group of individuals who meet regularly to discuss articles in current medical literature. The earliest reference to a journal club is found in Sir James Paget's memoirs and letters (1835-1854) in which he described how a small group of students near St. Bartholomew's Hospital London met in a room over a baker's shop to read journals. Evidence of the first formal journal club comes from McGill University MontrÈal where, in 1875, William Osler found a way to make expensive periodicals affordable by organizing with fellow students to purchase expensive journals at a group rate. Studies show that journal clubs promote critical thinking, reading habits and strengthening of collegial relationships. The journal club also has been advocated as a bridge between research and practice, hence facilitating better practice of evidence based medicine. Current internet technology has added another dimension to traditional journal club, where online discussions are the main stay of journal club. A study conducted in Pakistan aiming at reporting the existence and effectiveness of journal clubs has shown that a journal club can help residents develop the habit of staying updated on the significant literature that is published every year in medical science. Against the backdrop of a general resource constraint in developing countries, journal club has made effective use of information technology for selecting articles from reputed international journals online. 
Given the free access to 17,000 scientific journals online, by Higher Education Commission (HEC) of Government of Pakistan; public sector medical universities can utilize the approach of journal club to train postgraduate trainees to make their practice evidence based. This exemplary effort on the part of the HEC could provide a model for governments in countries where there are similar resource constraints. 15

Working environment has a direct implication on the exploitation of time and training opportunities. The training process includes trainers (consultants) and trainees (residents). Improving the working life for both reflects positively on the outcome of the training process. In a study conducted in the UK, the principle needs were better secretarial and managerial support. ${ }^{16}$ In day-to-day practice, non-medical personnel could carry out the non-clinical work, thereby saving human potential. This is important, since roughly $1 / 3$ rd of the time that residents of surgery in UK spend is used in work of bureaucratic or administrative nature. To save the time of the residents, direct application of modern technology like computerization of hospitals and electronic transmission of radiological pictures and results of laboratory examinations have been proposed. These changes, to a certain extent, will ameliorate the bad working conditions of doctors in the hospital. ${ }^{8}$

For our residents in Egypt, there is no doubt that much of their working hours are lost in "errands" that otherwise could have been done by other hospital personnel. This is well evident when comparing the performance of the same residents in different environments. Our unit in Demerdash (university public) hospital is run by 5-6 residents compared to 2 residents in Ain-Shams Specialized (university private) hospital for almost equal number of in-patients. The backup by secretarial, nursing, paramedical and administrative personnel as well as availability of better communication facilities (although not entirely perfect) makes this possible. Improving working environment in the public counterpart (e.g. Demerdash) will definitely provide more time to invest in learning and training.

In a study assessing trauma training in
Australia and New Zealand, only 32\% of general surgical trainees believed that their exposure to major trauma operations was very adequate despite an average of 12.3 trauma operations per year. Seventy per cent of general surgical trainees reported a very adequate level of consultant supervision at trauma operations. The study concluded that regional rotations may need to be developed to even out trainees' experience in trauma management. ${ }^{17}$

In Egypt, management of trauma patients is part of the service provided by the general surgery department in most if not all of our university hospitals. Apart from few university private hospitals (Specialized hospital of AinShams and New Kasr Al-Eini Hospital) there are no separate trauma units at which residents rotate. Each general surgery unit is allocated certain days to cover reception of trauma and casualty patients. Regarding the absolute numbers of trauma patients, our general surgery residents are exposed to adequate numbers but the utilization of this opportunity for adequate trauma management training might be suboptimal. General surgery residents as well as other residents in surgical specialties are trained each to limited procedures pertaining to their future specialties at time that each should be trained to all basic procedures during this early phase of their surgical training. Nowadays, it is hardly possible to find a general surgery resident trained to do an emergency tracheostomy or a resident of orthopaedics trained to introduce a chest tube. A rotation, rather than day allocation, to a separate trauma unit for residents of all surgical specialties should be considered. The setup of this unit must allow residents of various surgical departments to participate in all procedures while confining demanding specialized procedures to specialized consultants.

Special courses during a RTP were found to be an integral part of surgical training. Research was another essential component of surgical training. One of the proposed courses for all residents was that on Advanced Trauma Life Support (ATLS). ${ }^{18}$ In Burmingham, UK, a questionnaire posted to consultants as well as trainees has shown that research was felt to be essential for all trainees by 50 per cent of respondents. 86 per cent of trainees also thought that all potential academics should obtain a 
degree by thesis. A planned, supervised and funded one-year period of research was favoured by the majority of consultants (54 per cent) and trainees (73 per cent). ${ }^{19}$

In our present system, a thesis is required to fulfill requirements of applying to M.D. exam. We therefore need no crucial adjustments regarding this issue if we combine the present assistant lecturer and residency periods in one training period. The cost of a well designed research is often an obstacle for candidates. The issue of funding must therefore be addressed if a true value of a research is to be anticipated. Still financial support for special courses, say one per year, should also be considered.

Gaining experience in a different working environment has proved beneficial to incorporate in a residency program. In the USA, a 6 week clinical training in a developing country (Uganda) was tried as a pilot trial. This resulted in exposure of residents to the educational benefits of learning in a resourceconstrained setting: a broader scope of surgical conditions and pathology, greater reliance on history-taking and physical examination skills in a low-technology environment, and sociocultural aspects of care provision. ${ }^{20}$ Language barrier did not seem to influence overseas experiences negatively. In the past, young surgeons in Australia and England completed their training with periods spent in the UK or USA respectively. Surgeons who had training in non-English speaking countries report that this experience has furthered their training in their specialty. They recommend that surgeons in training may consider the possibility of additional experience in Europe rather than the UK or USA. ${ }^{21}$

For our residents, such an experience might entail a visit to a more developed country. Such a program would definitely add financial burden to the already limited resources in a developing country. An exchange residency program with one or more of the developed countries might solve this problem. Some assistant lecturers already get a chance of a variable training period abroad. If the period of assistant lecturer is to be incorporated in the training program of residents, as supposed to be, then probably a three month or so of training abroad would be possible.
Developing methods for evaluation of any training program is essential for making improvements and avoiding drawbacks. A measurement of how good a program meets its objectives must be set at time of development of the program itself. Part of this method is simply to develop a form where certain acquired skills are to be ranked by residents and trainers (consultants) as well. The Edinburgh Basic Surgical Trainee Assessment Form (EBSTAF) was developed in the UK and was proved to be a feasible, reliable and construct valid tool for assessment of surgical trainees. ${ }^{22}$

Training in surgical and other skill based specialties require structured supervised operating time. The Royal College of Surgeons of England has calculated that the number of hours available for training and gaining experience pre-Calman was around 30000 . This reduced to less than 10000 after the introduction of the European working time directive and is likely to fall to just over 6000 hours if the Modernising Medical Careers proposals to shorten specialist training are adopted. Another consequence of specialist registrars having to change hospitals frequently is that they are no longer one consultant's responsibility. Previously specialist registrars worked for three to five years with one team of consultants who individually or collectively provided mentoring and career support.16

For trainees to achieve an acceptable level of surgical operative competence, the learning environment in the operating theatre needs to be optimized.23 A study conducted in Edinburgh, UK, has shown that caseload assessment alone is inadequate to assess surgical training. In this study, the consultant was first assistant in 66 per cent of procedures performed by the Senior House Officers, 61 per cent by the registrar and in 13 per cent by the Senior Registrar. This better reflected the greater complexity of the operations performed by each trainee and the overall degree of surgical training. ${ }^{24}$

I doubt if our residents are assisted by a consultant in $61 \%$, or a near figure, of the operations they perform. The factor of 'who was the assistant?' will be essential when developing our domestic RTP. Consultants, in our case university staff, must then accept this 
additional load as definite scheduled responsibility rather than a matter of occasional kindness. A mechanism for imposing such a duty on university staff members who are unwilling to comply voluntarily must be established. Probably a consideration of how much assistance was provided to residents should be made when applying for upgrading to posts such as assistant professor and professor.

Despite crucial differences, still the French residency training system is probably one of the most systems in western countries with which our residency and assistant lecturer periods of training can adapt easily. Therefore, it might be worthy to take a closer look at the general and gastrointestinal tract surgery training in France. In France, forty-three staterun medical schools admit 30000 students per year but only 3500 receive their diploma after 6 years of studies. After passing a special examination, 480 of 2000 residents choose surgery and train during twelve 6-month rotations. There are 43 medical schools in France, all affiliated with the state-run universities to which they belong. They are staffed by about 3500 persons (for the entire country) who have been appointed "professor" by the Ministry of Education and they do their teaching in the region to which they belong. All professors are bi-appartenant; ie, they are responsible for teaching but also have clinical activities. Their mission is actually triple, however, as they additionally have research activities. Each medical school is headed by a dean, who is elected by the council of each university. The council is a representative body composed of professors, nonuniversity heads of service, chief residents, residents, students, and civil officers. Future specialists are required to pass a special competitive entrance examination called the Internat in their sixth year of studies. When this examination is passed, the medical student has the title of Interne des Hôpitaux, the equivalent of "resident" in the United States. About 8.6\% of students choose surgical specialties per year. All future specialists in surgery are required to do six 6-month rotations, at least 2 in visceral and 2 in orthopedic surgeries. This part of training is also called the "common trunk". During this 3-year period, the resident follows theoretical courses provided by the faculty and has hospital ward responsibilities, is on 24hour call duty, and assists in operating room procedures. Next comes the Diplôme d'Etudes Spécialisées Complémentaire, another series of 6-month rotation periods that last for a total of 3 years ( 2 as an interne and 1 as a chef-declinique), where the apprentice surgeon is in his or her area of specialization, for instance, digestive or gastrointestinal tract, orthopedic, vascular, or other surgery. At the end of the first 3-year period, the student obtains his or her diploma in general surgery, as long as at least 4 rotations were either in general, gastrointestinal tract, or orthopedic surgery. At the end of the 6-year period, the surgeon has to present a "memoir." All along these 6 years are courses provided once a month concerning theoretical and practical aspects of surgery. After the initial 5 years of training, the interne becomes a chief resident (chef-declinique) for a minimum of 2 years. If the resident wishes to continue in the hospital system or pursue an academic career, he or she has to obtain a Diplôme d'Etudes Approfondies (Diploma of Advanced Studies) during this same training period, or during the 2 years following the initial training period. In 1998, there were approximately 56 professors in gastrointestinal tract surgery and 112 in general surgery in France. ${ }^{25}$

Another model of a two-staged or twoleveled training is that adopted in Hong Kong. Surgical training consists of two years of basic training after the internship followed by at least four years of higher training. A basic surgical trainee must attach to a university and pass an examination before entering into the higher training level. Only at this level will a trainee start subspecialty training and will choose among these options: cardiothoracic surgery, neurosurgery, plastic surgery, paediatric surgery, plastic surgery, urology, orthopaedics, emergency surgery, otolaryngology or continue general surgery. At least four years later, only those who fulfilled all the requirements of this higher training are allowed an exit exam to become a specialist. Some specialties like neurosurgery and cardiothoracic surgery require longer higher training than the four years. 26

The development of a body of interest, like 
of trainees themselves, when setting a program might prove more beneficial than developing a program by, say, senior consultants alone. The Permanent Working Group of European Junior Hospital Doctors (PWG) represents the interests, in international matters, of trainees from 23 member states. The PWG recognizes the importance of postgraduate training (PGT) in the maintenance of high quality health care delivery. The PWG recommended that the views of the consumers of PGT, the trainees, are more fully considered in the development of training programs. 27 The PWG, not only cares for interests of young doctors, but has proved useful in providing useful data through conducting studies all over Europe. PWG conducted a survey among surgical trainees in member countries with the aim of describing postgraduate training in surgery throughout Europe. In each country, 10 trainees with surgical training of 2-5 years and 10 trainees with surgical training of 6-9 years answered a questionnaire. A trainee had to care for an average patient load varying from 30 to 80 patients at any one time. The average number of working hours ranged from 52 to $88 \mathrm{~h}$ per week, including up to $18 \mathrm{~h}$ of unpaid work. The different tasks carried out within these working hours varied considerably, as did the proportion of tasks with educational value. Trainees participated in four to 11 major operations each week, but the number of operations a week did not reflect the number of operations conducted under supervision. In some countries, the majority of the trainees stated that they received their training mainly through unsupervised experience. The average number of days spent on courses and congresses varied from 4 to 15 days per year, with great variation in the percentage of expenses paid. ${ }^{28}$

Interestingly, when evaluating the changes previously set by Calman, observers often refer to post -change era as the "Calman or postCalman period" while they refer to the process of change itself as "Calmanisation". These terms are often ambiguous for a non- western person, like me, reviewing this topic for the first time but the terms seem so familiar in the western literature dealing with post-graduate training. A study in 2004 assessing the outcome of Calmanisation, over a decade from its start, has concluded that 'specialist registrars' appear to be gaining less operative experience than their predecessors in both the elective and emergency settings. However, the reduced operative experience was not entirely the result of Calmanisation but was due also to the environment changes at work. It was unfortunate that at time Calman changes were started, a chronic shortage in healthcare expenditure started as well. There were inadequate ward beds and high care facilities. There were insufficient nurses to cover the available beds leading to frequent cancellations of admissions and operations. Till working environment could be improved the study concluded that the solution lies either in reincreasing working hours as pre-Calman.; otherwise to increase the duration of training and reintroduce the concept of senior registrars or 'specialty registrars' ${ }^{29}$

Now, to reach the most sensitive issue: The reforms in the training programs have added increasing responsibilities on the trainers in surgery (consultants). There is little relevant literature on the professional surgical and nonsurgical attributes inherent in a good trainer in general surgery. Studies have concentrated on the content of surgical training programs or trainees' needs and assessment rather than the required attributes of trainers themselves. A study has defined the top ten attributes required in a trainer in the UK. In descending order these attributes were: to have a high level of operative and clinical competence, to show interest in the trainee, to treat all junior staff with respect, to know own limitations, to be someone a trainee can respect clinically and professionally, to know when to let the trainee do the operation on his/her own, to be approachable, to engender self confidence in the trainee, to demonstrate logical assessment of emergency admissions and to demonstrate the importance of safety. ${ }^{30}$ Most western surgical communities are willing to address issues as evaluating trainers themselves and to ask questions as 'training for trainers'? Whether we are similarly willing to discuss this or do we find ourselves, unquestionably, better trainers than our counterparts? I leave the answer to this question for the readers to decide. 


\section{References:}

1- Himmel W, Kochen MM: How do academic heads of departments of general practice organize patient care? A European survey. Br J Gen Pract 1995; 45(394): 231-234.

2- Paice E, Aitken M, Cowan G, Heard S: Trainee satisfaction before and after the Calman reforms of specialist training: questionnaire survey. BMJ 2003; 320(7238): 832-836.

3- Crofts TJ, Griffiths JMT, Sharma S, Wygrala J, Aitken RJ: Surgical training: an objective assessment of recent changes for a single health board. BMJ 1997; 314: 891

4- Lampert VD, Heberer M, Harder F: Surgical training in Switzerland. Ann Chir 1994; 48(5): 462-469.

5- Stipa S, Ziparo V, Castorina S: Health care delivery systems: effects on surgical education in Italy. World J Surg 1994; 18(5): 692-694.

6- Mittal V, Salem M, Tyburski J, Brocato J, Lloyd L, Silva Y, Silbergleit A, Shanley C, Remine S: Residents' working hours in a consortium-wide surgical education program. Am Surg 2004; 70(2): 127-131.

7- Lo SF, Spurgeon P: Working hours of surgical residence: perspective of a group of surgeons in a regional hospital in Hong Kong. Asian J Surg 2007; 30(1): 60-66.

8- Sakorafas GH, Tsiotos GG: New legislative regulations, problems, and future perspectives, with a particular emphasis on surgical education. Educational Forum 2004; 50(4): 274-277.

9- Degrieck N: A critical view on the surgical training. Acta Chir Belg 1994; 94(3): 170172.

10-Driller C, Holschneider AM: Training in pediatric surgery - A comparison of 24 countries in Europe. Eur J Pediatr Surg 2003; 13: 73-80.

11-Wolfe JH: General surgical training: improvements and problems. Ann R Coll Surg Engl 1998; 80(3 Suppl): 112-1160.

12-Horvath KD, Mann GN, Pellegrini C: EVATS: a proactive solution to improve surgical education and maintain flexibility in the new training era. Curr Surg 2006; 63(2): 151-154.

13-Heard JK, Allen RM, Clardy J: Assessing the needs of residency program directors to meet the ACGME general competencies. Acad Med 2002; 77(7): 750.

14-Roth CS, Watson KV, Harris IB: A communication assessment and skillbuilding exercise (CASE) for first-year residents. Acad Med 2002; 77(7): 746-747.

15-Akhund S, Kadir MM: Do community medicine residency trainees learn through journal club experience from a developing country. BMC Medical Education 2006; 6: 43.

16-Dornhorst A, Cripps J: Improving hospital doctors' working lives: online questionnaire survey of all grades. Postgraduate Medical Journal 2005; 81: 49-54.

17-Thomson BN, Civil ID, Danne PD, Deane SA, McGrath PJ: ANZ J Surg 2001; 71(2): 83-8.

18-Graham CA, Sinclair MT: A survey of advanced trauma life-support training for trainees in acute surgical specialties. Injury 1996; 27(9): 631-634.

19-Kmoit WA, Neoptolemos JP, Temple JG: Research in higher surgical training: the West Midlands view. Ann R Coll Surg Engl 1993; 75(5 Suppl): 147-149.

20-Ozgediz D, Roayaia K, Debas H, Schecter W, Farmer D: Surgery in developing countries: essential training in residency. Arch Surg 2005; 140(8): 795-800.

21-Maddern GJ, Dennison AR: Central European surgical training. Aust N Z J Surg 1992; 62(5): 397-399.

22-Discoll PJ, Paisley AM, Paterson-Brown S: Trainees' opinions of the skills required of basic surgical trainees. Am J Surg 2003; 186(1): 77-80.

23-Cassar K: Development of an instrument to measure the surgical operating theatre learning environment as perceived by basic surgical trainees. Med Teach 2004; 26(3): 260-264.

24-Potter MA, Griffiths JM, Aitken RJ, Crofts TJ: An objective assessment of surgical training. Ann R Coll Surg Engl 1996; 8(1 Suppl): 11-13.

25-Fingerhut A, Hay JM, Millat B, Lacaine F, Fagniez PL: General and gastrointestinal tract surgery in France. Arch Surg 1998; 133: 568-574.

26-Lau WY, Lai ECH: Surgical practice in Hong Kong. Surgeon 2006; (5): 259-264. 
27-Borman E, O'Grady P: Postgraduate training. Policy paper prepared by the Subcommittee on Postgraduate Training: Permanent Working Group of European Junior Hospital Doctors. Med Educ 1997; 31(1): 3-8.

28-Kay L, Pless T, Brearley S: Survey of surgical training in Europe. Med Educ 1996; 30(3): 201-207.

29-Morris-Stiff G, Ball E, Torkington J, Foster
ME, Lewis MH, Havard T: Registrar operating experience over a 15 -year period: More, less or more or less the same? Surg $J$ R Coll Surg Edinb Irel 2004; 2(3): 161164.

30-Ker JS, Williams B, Reid M, Dunkley P, Steele RJC: Attributes of trainers for postgraduate training in general surgery a national consensus. Surg $J$ R Coll Surg Edinb Irel 2003;1(4):215-220. 